\title{
RELAÇÕES DE GÊNERO E RELIGIÃO: ANÁLISE DAS PRÁTICAS RELIGIOSAS DA SANTERIA EM CUBA*
}

\author{
Naile Braffo Conde*
}

\section{RESUMO}

A religião, como parte integrante do sistema social, estabelece conexões dentro das suas estruturas, seja na construção de representações sociais como na legitimação ou dissimulação de jogos de poder. O presente artigo busca abordar essa relação no sistema religioso Regla de Ocha ou Santería em Cuba, a partir de uma análise do sistema sexo-gênero e das relações sociais construídas por muIheres e homens no interior das práticas religiosas. Este trabalho não pretende defender hipóteses, apenas apresentar tendências sobre a relação em questão. A análise é baseada em abordagens, percepções e comportamentos de um grupo de 26 mulheres e 12 homens praticantes do sistema religioso, entrevistadas/os e observadas/os durante o desenvolvimento das práticas religiosas.

Palavras-chave: Santeria; Cuba; sistema sexo-gênero; relações de gênero; relação religião-gênero.

\section{GENDER RELATIONS AND RELIGION: ANALYSIS OF THE RELIGIOUS PRACTICES OF SANTERIA IN CUBA}

\section{ABSTRACT}

Religion, as an integrant part of the social system, establishes connections within its structures, both in the construction of social representations or legitimizing or masking power games. This article

* O presente trabalho foi realizado com apoio do Programa de Estudantes-Convênio de Pós-Graduação (PEC-PG), da CAPES/CNPq - Brasil.

** Doutoranda do Programa de Pós-Graduação em Ciências da Religião da Universidade Metodista de São Paulo e integrante do Grupo de Estudos de Gênero e Religião Mandrágora/Netmal. 
seeks to approach this the gender relations in the practices of the religious system Regla de Ocha or Santeria in Cuba, based on the analysis of the sex-gender system and the social relations built within religious practices. It does not intend to defend any hypotheses, but to present trends about these relations. The analysis is based on approaches, perceptions, and behaviors of a group of 26 women e 12 men practitioners, interviewed and observed during the development of religious practices.

Keywords: Santeria; Cuba; sex-gender system; gender relations; religion-gender relationship.

\section{RELACIONES DE GÉNERO Y RELIGIÓN: ANÁLISIS DE LAS PRÁCTICAS RELIGIOSAS DE LA SANTERIA EN CUBA}

\section{RESUMEN}

La religión, como parte integrante del sistema social, establece relaciones al interior de sus estructuras, sea en la construcción de representaciones sociales, como en la legitimación o enmascaramiento de juegos de poder. El presente trabajo busca aproximarse a esa relación en el sistema religioso Regla de Ocha o Santería en Cuba, a partir del análisis, desde el sistema sexo-género, de las relaciones sociales construidas, por mujeres y hombres, al interior de las prácticas religiosas. Para nada pretende defenderse hipótesis, tan solo divisar tendencias sobre dicha relación. El análisis tiene por base planteamientos, percepciones, comportamientos de un grupo de 26 mujeres y 12 hombres practicantes, entrevistadas/os y observadas/ os durante el desarrollo de las prácticas religiosas.

Palabras clave: Santería; Cuba; sistema sexo-género; relaciones de género; relación religión-género.

As mudanças de uma época histórica sempre podem ser determinadas com base no progresso das mulheres em direção à liberdade [... ].

O grau de emancipação feminina constitui a medida natural da emancipação geral.

Karl Marx

\section{INTRODUÇÃO}

A religião é um fenômeno que não está longe da influência da reflexão e reprodução simbólica de uma sociedade patriarcal e, por isso, 
está condicionada à interpretação de homens e mulheres, a partir do contexto social correspondente. As qualificações de gênero emanam de sistemas religiosos, como o do sistema cubano de origem africana, a Regla de Ocha ou Santeria, e de estereótipos sexistas construídos por um conjunto de valores e normas incorporados que, em sua evolução histórica, foram influenciados pelas culturas predecessoras.

Desde o final do século $X X$, há um debate que parte do sistema sexo-gênero ${ }^{1}$ para abordar os processos de colonização ocidental, tal qual acontece nos estudos sobre as culturas africanas. Este sistema, como um fenômeno associado à colonização ocidental na África, e não como um fenômeno essencial dos/as africanos/as pré-colonizados/as, influenciou uma mudança radical na maneira de perceber esses povos.

De outra parte, a interseccionalidade na teoria da colonialidade do poder, proposta por Aníbal Quijano (2009), apresenta uma reflexão sobre as categorias raça e gênero enquanto uma construção mental, instituídas na naturalização das diferenças biológicas - cor da pele e sexo - e estabelecidas no processo de colonização. Argumenta-se que tais categorias constituem mecanismos de poder - além do marco da colonização - implementados para justificar, desde uma perspectiva ideológica, a relação de superioridade-inferioridade estabelecida em um sistema de relações sociais de discriminação.

Nesse debate, há referências às instituições de gênero e à família patriarcal hegemônica, como destaca Rita Segato (2012), embora, no cotidiano, constantemente sejam introduzidos sinais que corroem e deslegitimam a ordem imposta. Trata-se de uma intensidade patriarcal que permite abertura ao trânsito e à circulação entre as posições de gênero, proibidas em seu equivalente moderno ocidental. São ideias baseadas na diáspora africana e nos processos de colonização, como os que ocorreram no Brasil (Rita SEGATO, 2012). Daí a importância de

A distinção do sistema sexo-gênero constitui uma construção sociocultural em uma base biológica que se torna um elemento estruturante de qualquer sociedade. Isso considera o sexo como um conjunto de características físicas, biológicas, anatômicas e fisiológicas que distinguem os seres humanos e permitem diferenciar homens e mulheres desde o nascimento. Refere-se a hormonais, cromossômicos, hipotalâmico-hipofisários, endócrinos, genitais e fenotípicos. Em suma, o sexo refere-se às diferenças biológicas entre homens e mulheres (Mareleen DíAZ, 2009, p. 2, tradução própria). 
estudar as relações estabelecidas e os processos de participação social de homens e mulheres a partir dos contextos sócio-históricos em que são desenvolvidos.

[... ] uma construção sociocultural e histórica sobre o conjunto de características, funções, significados, identidades, relações e comportamentos atribuídos às pessoas de acordo com o sexo [...] (Mareleen DÍAZ, 2009, p. 3, tradução própria)².

As mulheres são vítimas de processos de desigualdade social, seja por conta das diferentes restrições que lhes são impostas, pela minimização de seus atos devido à sua condição genérica, pela subestimação da capacidade de desempenho de funções com o mesmo nível de responsabilidade e qualidade do homem ou pelas limitações de participação nos mesmos espaços sociais que os homens. Isso não foge à lógica de funcionamento dos diferentes sistemas religiosos, cujas discriminações se sustentam em estereótipos de gênero ${ }^{3}$ baseados em diretrizes de uma sociedade patriarcal.

Tais processos apresentam mecanismos que evidenciam uma realidade não igualitária para as mulheres, na qual os padrões culturais são assumidos a partir de normas ditadas por uma sociedade machista e sob a lógica da divisão sexual do trabalho.

A divisão sexual do trabalho é entendida como uma distribuição desigual dos papéis sociais; bem como que foi um processo determinante para aquela diferenciação genérica que se deu na sociedade [...]. Isso significou também uma distribuição desigual dos espaços e atividades sociais exercidas pelos sexos, bem como a feminização e masculinização das atividades e territórios de interação. Dele derivou-se uma estrutura de relações genéricas a partir da hierarquia de papéis e

$2[\ldots]$ una construcción sociocultural e histórica sobre el conjunto de características, funciones, significados, identidades, relaciones y comportamientos que se atribuyen a las personas de acuerdo a su sexo [...] (Mareleen DÍAZ, 2009, p. 3).

3 Os estereótipos de gênero legitimam essas normas e valores que as sociedades patriarcais instituem e, por sua vez, regulam os comportamentos sociais das pessoas. Nessas sociedades e / ou espaços sociais, onde estes estereótipos predominam as mulheres são estigmatizadas como o sexo fraco, e toda a supremacia é para os homens. 
status, o que colocou as mulheres em situação de inferiorização na vida familiar e pública (Reina FLEITAS, 2005, p. 43-44, tradução própria) $)^{4}$.

As reflexões de Fleitas (2005) apresentam como as relações de gênero influenciam na reprodução das relações de poder, visto que estas podem se tornar formas de expressão de violência. Tal diversidade de classificações e expressões de violência de gênero, às vezes institucionalizada, nega a participação das mulheres em igualdade de direitos. Portanto, faz-se necessário incorporar a perspectiva de gênero na pesquisa social contemporânea, pois esta abordagem permite romper com as bases discriminatórias e níveis desiguais de participação entre mulheres e homens nos diferentes espaços sociais.

As relações que se estabelecem nos diferentes sistemas religiosos também passam pelas lógicas anteriormente descritas. É através da religião, como reflexo da sociedade à qual faz parte, que também se reproduzem visões e distinções no que se refere ao feminino e ao masculino. Isto é, as relações geradas no interior das religiões são espelhos das relações materiais e sociais que se desenvolvem nas sociedades onde estes sistemas religiosos estão incorporados. Atualmente, mesmo com a abertura à participação feminina mais efetiva nos diferentes processos sociais, ainda existem desigualdades e diferenciações, seja no acesso às oportunidades ou às possibilidades de participação no espaço religioso.

Portanto, a intenção deste trabalho é apresentar tais tendências nas relações de gênero que se estabelecem no interior do funcionamento da Regla de Ocha ou Santería em Cuba, destacando a legitimação das relações de poder e a desigualdade entre mulheres e homens seguidoras/es neste sistema religioso. Os resultados aqui apresentados fazem

4 La división sexual del trabajo es entendida como desigual distribución de papeles sociales; así como que fue un proceso determinante para esa diferenciación genérica que se operó en la sociedad [...] Esta significó, además, desigual distribución de los espacios sociales y de las actividades realizadas por los sexos, así como la feminización y masculinización de actividades y territorios de interacción social. De ella se derivó una estructura de las relaciones genéricas sustentadas en la jerarquización de roles y estatus, que estableció a la mujer en una situación de inferiorización en la vida familiar y la pública (Reina FLEITAS, 2005, p. 43-44). 
parte dos achados da dissertação de mestrado, acrescidos de dados parciais da atual pesquisa de doutorado ${ }^{5}$, ambas desenvolvidas pela autora deste trabalho. Os dados baseiam-se em entrevistas e observações de práticas religiosas com 26 mulheres e 12 homens praticantes da Regla de Ocha ou Santeria em Cuba.

\section{O SISTEMA RELIGIOSO REGLA DE OCHA OU SANTERIA}

A transformação que envolveu a chegada de negros/as africanos/ as às terras cubanas sob sinais de escravidão e marginalização, bem como o processo de encontro com outras culturas, contribuiu para uma importante readaptação simbólica de práticas religiosas e culturais.

A escravidão provocou uma mudança do sistema religioso e, ao mesmo tempo, uma transformação na natureza de suas práticas, visto que negras/os africanas/os escravizadas/os foram explicitamente alienadas/os às novas formas de produção.

Isto implicou em mudanças nas estruturas simbólicas, como o sincretismo dos panteões ou a ressignificação das formas dos símbolos religiosos, assim como nas relações sociais que os caracterizam como sistemas religiosos.

Tanto as mudanças em suas estruturas, quanto o surgimento de novos papéis e as novas formas de se relacionar com e em uma sociedade incompatível com seus pressupostos ideológicos e comportamentais originais, foram elementos que contribuíram, juntamente com a coexistência de diferentes grupos étnicos, para a geração de variações fundamentais que permitiram o desenvolvimento dos atuais sistemas religiosos da sociedade cubana, entre eles a Regla de Ocha ou Santeria.

Esse sistema religioso é composto por dois segmentos: o primeiro é aquele que adora totalmente os orixás (segmento Ocha); e o segundo, o culto Ifá (segmento Ifá), relacionado a Orúla (máximo adivinho do panteão lorubá). Tem como base da estrutura organizacional a família religiosa (grupo religioso), um grupo social que estrutura o sistema e reúne os elementos mais importantes deles: as crenças, as práticas e a organização (estrutura-função). A vida da família religiosa é o principal

Esta tem por objetivo explicar processos de desigualdade social entre praticantes desse sistema religioso no contexto das mudanças que a sociedade cubana experimenta desde 2009. 
espaço de orientação das/dos suas/seus integrantes e é nesta que as diferentes relações sociais geradas se manifestam de maneira estruturada. Assim, seu crescimento ocorre de maneira não programada, ramificada e descentralizada.

A cosmologia derivada do sistema Regla de Ocha ou Santeria mantém a crença em seus ancestrais em que todas as forças visíveis da natureza, inclusive as ações humanas, são guiadas por formas e motivações não visíveis (Lázara MENÉNDEZ, 2008). Portanto, se caracteriza como um sistema de crenças articulado com mitologias, lendas - conhecidas entre seus praticantes como patakíes -, seres ou forças sobrenaturais - o culto de divindades e ancestrais -, natureza, oferendas e sistemas de adivinhação ${ }^{6}$. Esses elementos mostram o quão complexo e diversificado é o espectro de base no funcionamento deste sistema religioso.

Desde a última década do século $\mathrm{XX}$, esse sistema religioso aumentou seu nível de visibilidade na sociedade cubana (DESR, 2006). Ao mesmo tempo, aumentou o reconhecimento popular de suas práticas, bem como os cultos no sentido de expansão entre os diferentes setores da população. Se constitui como uma comunidade religiosa em que suas/ seus membras/os estão em contato com orixás e, de acordo com suas formas de crescimento, compõem redes de relacionamentos que as/os ajudam a conduzir tanto suas vivências quanto o desenvolvimento de suas experiências religiosas (Naile BRAFFO CONDE, 2015).

6 Em Cuba, existem 4:

Coco, Obi ou Biagué: sistema de adivinhação mais simples da Regla de Ocha ou Santeria. É usado para obter uma resposta imediata pelo sim ou pelo não. São utilizados 4 pedaços de coco que, assim que jogados, podem ser lidos de cinco maneiras diferentes (em relação à parte branca e escura), formando cinco letras ou oddúns do sistema de adivinhação: alafia, itagua, eyeife, okana e oyekún.

Búzios ou Dilogún: são utilizados 16 búzios chamados cauris, que são jogados em uma esteira, cuja leitura é feita a partir do número daqueles que caem em suas costas, que formam as letras ou oddún do Dilogún; em cada um aparece um ou vários patakíes e certo número de conselhos, provérbios e medidas a serem tomadas para resolver os problemas da vida do consultor.

Okuele ou Ekuele: é um tipo de rosário ou cadeia de adivinhação, em sua maioria compostos por 8 pedaços de cascas de coco.

Tablero de Ifá: 16 sementes pretas de palmeira, conhecidas como ikis ou ikines, usadas ao lado de uma tábua de madeira redonda. O oráculo é governado por Orúla, orixá de adivinhação, e é manipulado pelos babalawo.

Mandrágora, v.27, n. 2, 2021, p. 115-133 
As/os praticantes têm uma vida religiosa regulamentada por normas tanto para o desenvolvimento das práticas como para sua projeção e seu comportamento social. As normas, ou regras, como expressam, formam uma combinação de preceitos estabelecidos pelos ramos religiosos, bem como pela maneira de conceber a religião da/o líder religiosa/o da família, sob o princípio da mistura entre passado e presente que permite uma readaptação aos momentos históricos e suas particularidades.

No que diz respeito ao sistema de práticas, este se constitui como um conjunto complexo de atividades religiosas, ritos e/ou cerimônias que cumprem certas funções e objetivos dentro do sistema religioso. As cerimônias representam o relacionamento das/os praticantes com suas divindades.

As cerimônias apresentam particularidades e complexidades de acordo com os estilos de trabalho de cada família religiosa. Isso ocorre porque o sistema Regla de Ocha ou Santeria não possui centros especializados ou textos sagrados (assim como qualquer outro sistema de origem africana) que forneçam uma maneira única de realizar cerimônias. Por outro lado, como consequência dessa inexistência, todo o seu funcionamento é realizado nas casas das/os praticantes - ilé ocha ou também chamados de casas-templos - com adaptações e interpretações, caso sejam consideradas.

Outra característica que distingue a Regla Ocha ou Santeria é sua capacidade de relacionar-se - a partir de um processo de intercâmbio, ou de um processo de transculturação (Fernando ORTIZ, 1963) - com outras religiões como o Catolicismo, o Espiritismo7 e o Palo Monte (outro sistema religioso de origem africana de Cuba). Trata-se de um vínculo com cerimônias desses sistemas, característica da flexibilidade da Regla de Ocha ou Santeria em se relacionar em uma conexão contínua. Foi isso o que lhe permitiu gerar-se, reproduzir-se e modificar-se, como aconteceu em sua evolução sócio-histórica após a coexistência com vários modelos socioculturais, cada um acompanhado por diferentes religiões que influenciaram seu desenvolvimento.

Em Cuba os sistemas religiosos de origem africana, entre eles a Regla de Ocha ou Santeria, tiveram forte influência do androcentrismo

Na sua vertente cubana. Ver: Naile BRAFFO CONDE (2021). 
das sociedades patriarcais. A partir dessas interpretações, algumas funções dentro das práticas desta religião são limitadas aos homens devido a supostos preceitos religiosos, questão pela qual são negadas às mulheres certas prerrogativas e até mesmo direitos (Naile BRAFFO CONDE, 2015).

Considerando o acima referido, é curioso notar que, em relação aos seres sobrenaturais (orixás), existe uma distinção hierárquica que põe à frente um ser supremo, assim como em outras religiões, cuja identidade de gênero é inexistente.

Uma característica da Santeria que nos permite afirmar a grande flexibilidade de seu sistema de gênero é que, [...], na tradição lorubá, o Deus supremo, Olodumare, não tem sexo. Além disso, como os orixás se manifestam em avatares ou caminhos femininos e masculinos, uma vez que o sexo do santero não precisa corresponder ao sexo do orixá do qual é filho ou filha, podemos dizer que o gênero aparece na Santeria com uma fluidez e variabilidade que seriam completamente anômalas em nossa concepção ocidental das realidades e relações de sexo e gênero (Gabriela CASTELLANOS, 2008, p. 176, tradução própria) $)^{8}$.

O mesmo acontece com orixás cuja identidade de gênero é confusa, como a autora Lydia Cabrera apresenta em sua obra Yemayá e Ochún. Kariocha, iyalorichas e olorichas (1980):

[...] também é verdade, meus informantes mais autorizados me asseguram que, como os mais velhos, "Olokun é mulher e homem" andrógino. [...] "De sexo anfíbio" [...] Ele também fala dos amores entre lemanjá e Inle, andróginos: [...] que o sequestrou, levou-o ao fundo do mar e o manteve lá até saciada de todo seu apetite, ficou entediada dele e desejou voltar ao mundo na companhia dos outros

\footnotetext{
Un rasgo de la Santería que nos permite afirmar la gran flexibilidad de su sistema de género es que, [... ], en la tradición Yoruba el Dios supremo, Olodumare, no tiene sexo. Además, debido a que los orichas mismos se manifiestan en avatares o caminos tanto femeninos o masculinos, y a que el sexo del santero no tiene que corresponder al del oricha del cual es hijo o hija, podemos decir que el género aparece en la Santeria con una fluidez y una variabilidad que serían completamente anómalas en nuestra concepción occidental de las realidades y las relaciones de sexo y género (Gabriela CASTELLLANOS, 2008, p. 176).
} 
orixás e dos homens [...]. Iemanjá com suas sete saias [...] ninguém sabe o que ela esconde por baixo "quando ela fica com raiva e reage como um homem” (Lydia CABRERA, 1980, p. 28-70, tradução própria). [...] Iansá que lutou ao lado de Xangô [...] lutou ao lado dele como um homem. Quando lansá puxava um facão para cortar cabeças ou caia no meio da batalha disparando raios e flashes, ele tinha barba e bigode (Lydia CABRERA, 1980, p. 73, tradução própria)`9

Não há fontes que apresentem Deus lorubá como não-antropomórfico (Rita SEGATO, 2003) e sem caracteres de gênero, e seus praticantes reconhecem que existe um deus supremo, arquiteto do universo, uma verdadeira incógnita na história de qualquer religião. Por outro lado, orixás são representadas/os mimeticamente por corpos de seres humanos e com seus respectivos componentes de gênero, o que não significa necessariamente um impacto na identidade de gênero entre as pessoas.

A partir da análise de Oyérònke Oyewùmí $(1997)^{10}$ sobre o sistema sexo-gênero, Segato (2003) apresenta como a análise do sistema sexo-gênero é resultado do próprio processo de colonização ocidental e não das lógicas de relacionamento das sociedades africanas, como nas terras de Oyó, reino lorubá, antes da colonização.

[...] para sublinhar o fato de que, no sentido do mundo lorubá, era possível conhecer essas distinções fisiológicas sem projetar uma hierarquia inerente às duas categorias sociais. Ao contrário do "macho" ou "fêmea" no Ocidente, as categorias obinrin e okunrin eram exclusivamente categorias relacionadas à anatomia e não permitiam suposições adicionais sobre personalidades ou psicologias derivadas dessa distinção puramente anatômica. Assim foi, porque não

9 [... también es cierto, me aseguran mis más autorizados informantes que como a sus mayores que "Olokun es mujer y hombre" andrógino. [...] "De sexo anfibio" [...] Cuenta además los amores entre Yemayá e Inle, andrógino: [...] que lo raptó, lo llevó al fondo del mar y allí lo tuvo hasta que saciada de todo su apetito, se aburrió de su amante y deseó regresar al mundo a la compañía de los demás orichas y de los hombres [...]. Yemayá con sus siete sayas [...] nadie sabe lo que esconde debajo "cuando se enoja y reacciona como un varón”. (Lydia CABRERA, 1974, p. 28-70).

[... ] Oyá que luchó junto a Changó [... ] peleaba a su lado como un hombre. Cuando Oyá halaba machete para cortar cabezas o caía en medio del combate disparando rayos y centellas, le salía barba y bigote. (Lydia CABRERA, 1974, p. 73).

10 Em The invention of women: making an African sense of western gender discourse. 
foram elaborados como uma relação de oposição entre si e, nesse sentido, não eram sexualmente biomórficos e, consequentemente, não receberam atribuição de gênero. No Oyó antigo, eles não conotavam hierarquia social nem expressavam masculinidade ou feminilidade, pois essas categorias não existiam nem na vida nem no pensamento Iorubá (Oyewùmí, 1997, p. 34 apud Rita SEGATO 2003, p. 337-338, tradução própria).

[...] a interpretação usual das categorias Iorubá obinrin e okunrin como "fêmea / feminino" e "macho / homem", respectivamente, é uma tradução incorreta [...] porque (entre os Iorubás pré-coloniais) essas categorias não eram binárias opostas nem eram hierárquicas [... ] (Oyewùmí, 1997, p. 32-33 apud Rita SEGATO 2003, p. 337-338, tradução própria). ${ }^{11}$

\section{RELAÇÕES DE GÊNERO NAS PRÁTICAS RELIGIOSAS DA REGLA DE OCHA OU SANTERIA}

As relações de gênero na Regla de Ocha ou Santeria são desenvolvidas sob condições de afastamento e ruptura às quais foram submetidas as famílias religiosas em Cuba. Os casais e descendentes não constituíam famílias nem grupos religiosos de linhagem. Assim, do ponto de vista hierárquico no universo da religião, a linhagem biológica foi substituída por uma família religiosa - não necessariamente biológica -, com as circunstâncias nas quais a mãe e/ou pai de santo desempenham um papel de liderança como guias do grupo religioso (Naile BRAFFO CONDE, 2015).

1 [... ] para subrayar el hecho de que en el sentido del mundo Yoruba era posible conocer esas distinciones fisiológicas sin proyectar una jerarquía inherente a las dos categorías sociales. A diferencia de "macho" o "hembra" en el Occidente, las categorías obinrin e okunrin eran exclusivamente categorías relativas a la anatomía y no permitían mayores suposiciones sobre personalidades o psicologías derivadas de esa distinción puramente anatómica. Esto era así, porque no eran elaboradas como una relación de oposición entre sí y, en este sentido, no eran sexualmente dimorfas y consecuentemente no recibían atribución de género. En la antigua Oyó no connotaban jerarquía social ni expresaban masculinidad o feminidad, ya que esas categorías no existían ni en la vida, ni en el pensamiento Yoruba (Oyewùmí, 1997, p. 34 apud Rita SEGATO 2003, p. 337-338).

[... ] la interpretación usual de las categorías Yoruba obinrin y okunrin como "hembra/mujer" y "macho/hombre", respectivamente, es una traducción equivocada [...] porque (entre los Yoruba pre-coloniales) esas categorías no se oponían binariamente ni eran jerárquicas [... ] (Oyewùmí, 1997, p. 32-33 apud Rita SEGATO 2003, p. 337-338).

Mandrágora, v.27, n. 2, 2021, p. 115-133 
Por um lado, as mulheres ocupam uma posição de possível igualdade com relação aos homens - lyalochas ${ }^{12} /$ Babalochas $^{13}$, Oyubona ${ }^{14} /$ lyubbón ${ }^{15}$-, enquanto, por outro, são localizadas em posição de inferioridade devido a certas limitações que favorecem os homens e cuja origem e justificativa não são conhecidas, uma vez que não se refletem no Dilogún ${ }^{16}$ (Tratado dos odduns) (Naile BRAFFO CONDE, 2015).

As mulheres seguidoras deste sistema religioso não dirigem cerimônias e nem usam sistemas divinatórios com alto grau de complexidade, pelo menos não na atualidade ${ }^{17}$. Os homens deram a isso uma explicação conveniente a eles, relacionada a estereótipos sexistas e discriminatórios, ou seja, as mulheres são impedidas de receber segredos da religião como foram Ozaín e Añá, de fazer o toque do tambor, de dar coco a Eggun ${ }^{18}$ e de matar animais quadrúpedes - mesmo que se tenha recebido o poder do Pinaldo (poder da faca) -, devido à fragilidade, indiscrição, desrespeito - de acordo com os homens entrevistados - e à sua natureza biológica (menstruação) que se refere a sujeira e impureza.

Aconteceu que uma mulher chamada Nana Burukú passada da idade de casar e sem marido, fez um pedido a Olofin e ele disse: - Você quer um marido? O terás. Procurou por Oggundaché, que estava sentado em uma pedra no meio da montanha, pensando que todos tinham tudo, menos ele, que até inclusive não tinha comida, porque ele não tinha axé para caçar. Com arco e flecha, meditava sua situação quando Olofin chegou e disse-Ihe que queria casá-lo com Nana Burukú, e ele concordou e assim fizeram.

\footnotetext{
Santera.

Santero.

14 Segunda madrinha ou mãe de santo.

15 Segundo padrinho ou pai de santo.
}

16 Sistema divinatório mais conhecido como búzios ou Tratado de odduns. A partir das tiragens dos búzios, são definidas 16 letras (odduns), que podem ser combinadas entre si a um total de 256. Com as interpretações, as/os santeras/os assumem conselhos e/ou proibições para sua vida religiosa.

17 [...] no livro Dilogún, Yrminio Valdés fornece uma lista de mulheres que já trabalharam como tais: ña Caridade (deu o canildo Shangó Tedún), ña Resalía, Teres Teresita Ariosa, ña Merced, ña Belén, Calixta Morales, Guillermina Castel, Carmen Miró, Ramona Collazo [...]. (Daysi RUBIERA, 1999, p. 9, tradução própria)

18 Mortos, espíritos. 
Os dias se passaram e Ogundaché disse: - E como eu me ocupo da minha esposa se nunca caço nada? E Olofin disse-lhe: - A partir de hoje você terá axé para caçar, só que não vai matar os animais, mas você os levará aonde eu vou lhe indicar.

O local era uma cabana que ficava no meio da montanha, e a partir daquele dia, com um Ibbo-ozain que the deu um eggun que vivia em uma ceiba que estava lá, Oggundaché levou os animais vivos, porque quando ele se aproximava dos animais, eles ficavam paralisados pela ação do Ibbó-ozain. Levava os animais para a cabana que Olofin tinha indicado, onde sugava o sangue dos corpos dos animais e depois os devolvia a Oggundaché, quem os levava embora para sua casa.

Sua esposa Nana Burukú ficou surpresa ao ver que os animais não tinham sangue, e sua curiosidade como mulher a levou a perseguir o marido, mas já no mato o marido se perdeu e, enquanto continuava andando, encontrou a cabana e, através de uma das janelas, viu Olofin sugando o sangue dos animais. Foi surpreendida pelo eggun que morava no ceiba e cuidava dos arredores, que a levou prisioneira onde Olofin, que disse: - Você me pediu um marido e eu dei a você, e agora por curiosidade, o que você viu, você verá todos os meses. E a mulher foi para casa e, quando chegou, viu uma hemorragia em seu corpo [...] (Anibal ARGUELLES; Daysi RUBIERA, 1995, p. 28-29, tradução própria) ${ }^{19}$.

19 Aconteció que una mujer llamada Nana Burukú estaba pasada de edad casadera y no teniendo marido le hizo una súplica a Olofin, y éste le dijo: -Tú quieres marido? Lo tendrás. Y buscó a Oggundaché que se encontraba sentado en una roca en el medio del monte pensando que todo el mundo tenía de todo menos él, que hasta incluso carecía de comida, pues él no tenía aché para la caza. Y con el arco y la flecha meditaba su situación cuando llegó Olofin donde él estaba y le dijo que quería casarlo con Nana Burukú y él accedió y se casaron.

Pasaron los días y Ogundaché dijo: - y cómo mantengo a mi mujer si yo nunca cazo nada? Y Olofin le dijo: -desde hoy tendrás aché para cazar, sólo que no matarás los animales, sino que los llevarás donde voy a indicarte.

El lugar era una choza que había en el medio del monte y desde ese día con un Ibboozain que le dio un eggun que vivía en una ceiba que allí había, Oggundaché cogía los animales vivos, pues cuando él se acercaba a los animales los paralizaba por medio de la acción del Ibbóozain y él tomaba los animales y los llevaba a la choza que Olofin le indicó, donde le chupaba la sangre del cuerpo a los animales y después se los volvía a entregar a Oggundaché, quien se los llevaba a su casa.

Su mujer Nana Burukú le extrañaba que los animales carecían de sangre y su curiosidad de mujer la llevó a perseguir a su marido, pero ya en el monte el marido se le perdió y al seguir caminando dio con la choza y al mirar por una de las ventanas vio a Olofin chupándole la sangre a los animales y estando entretenida, el eggun que vivía en la ceiba y cuidaba los alrededores la tomó prisionera y la llevó ante Olofin quien le dijo: Me pediste un marido y te lo di y ahora por curiosa, lo que has visto lo verás todos los meses. Y se fue la mujer para la casa y al llegar vio una hemorragia por su parte [... ]. (Anibal ARGUELLES; Daysi RUBIERA, 1995, p. 28-29).

Mandrágora, v.27, n. 2, 2021, p. 115-133 
Como pode-se ver, a menstruação é concebida como punição e não como natureza biológica relacionada à fertilidade. Tais limitações e/ou proibições não são exclusivas das práticas religiosas de origem africana. Nas sociedades androcêntricas, por exemplo, a influência do mito genérico sobre a menstruação servia de justificativa para a discriminação sofrida pelas mulheres na esfera religiosa. Nas religiões tradicionais da África subsaariana, atribui-se às mulheres o qualificativo de impuras durante o período menstrual (Daysi RUBIERA, 1999). Essa diferença biológica é interpretada como substantiva, capaz de marcar diferenciações através da imposição de normas e/ou tabus que buscam justificar a intenção da subordinação feminina de forma natural.

O Dilogún contém o peso fundamental dentro da religião e é responsável por transmitir uma herança durante os anos de convivência religiosa. Acontece que seus mitos são abertos ao mundo religioso com certa liberdade de interpretação de sua essência filosófica e, assim, mais de uma mensagem pode ser deduzida. Nos odduns, não se faz justiça ao papel dos orixás. Nos patakíes, em sua generalidade, é instituído caráter de doçura, condescendência ao casal e à maternidade como caraterísticas dos orixás, mas os sinais de coragem, força e desafio no sexo feminino não são totalmente apreciados, nem lhe correspondem classificações positivas.

Olofin baixou os orixás na terra, e junto com seus axés trouxeram as funções de acordo com o sexo. Nesse sentido, as divindades masculinas eram responsáveis pela criação do ser humano, pelo conhecimento dos segredos de homens e mulheres, conhecer o trabalho das/os orixás, o poder da vida e da morte, abrir e fechar os caminhos, dominar os segredos da floresta e os poderes de cura das plantas, substituir a sorte ruim pela boa e vice-versa, causar guerra e destruição, em cuja atuação os orixás refletiam competências, eficácia, força, grosseria, violência e exercício do poder, características própria dos padrões tradicionais de masculinidade. Enquanto os papéis observados nos orixás são enquadrados na sexualidade, maternidade, fabricação dos utensílios para uso masculino, e / ou mensageiras de Olofin (Daysi RUBIERA, 1999, p. 72-78, tradução própria) ${ }^{20}$.

20 Olofi bajó los orichas a la tierra, junto con su aché trajeron las funciones de acuerdo con el sexo. En tal sentido, a las deidades masculinas les correspondió la creación del ser humano, el 
Todo esse sistema mítico relacionado ao poder, reflexo de uma religião construída sob o domínio dos interesses patriarcais, trouxe consigo limitações às funções das mulheres em muitas situações. É o caso do segmento Ifá ${ }^{21}$, no qual a figura feminina só pode ser apeterbí de Orúla e, ainda que iniciada sacerdotisa de Ifá (iyanifa), não tem reconhecimento pleno em sua consagração. Deduz-se que elas não podem acessar os sistemas de adivinhação utilizados pelo babalawo. Em sua parte no segmento Ocha, sequer são iniciadas como Oriatéz ${ }^{2}$.

Pelo exposto, praticantes explicam que as mulheres entregam ${ }^{23} \mathrm{e}$ recebem mais orixás femininos do que masculinos, e os homens mais orixás masculinos que femininos. Quando isso não se manifesta, as representações construídas são resultado da falta de feminilidade ou masculinidade, ou da presença de homossexualidade, segundo parte do grupo entrevistado, muito embora a correspondência entre o sexo das/os orixás e o das/os praticantes não seja necessária (Lázara MENÉNDEZ, 2002).

[... ] Existem orixás masculinos nas "cabeças" femininas e vice-versa [...]. Como a correspondência entre os sexos não é necessária, é possível projetar um tipo de contradição entre a autoimagem de muitos santeros em relação aos papéis de masculinidade e feminilidade socialmente aceitas, e a tipificação ritual atribuída ao sexo, segundo a prática e as histórias que compõem o corpus santero [...] (Lázara MENÉNDEZ, 2002, p. 154-155, tradução própria) ${ }^{24}$.

conocimiento de los secretos del hombre y de la mujer, conocer el trabajo de las/os orichas, el poder de la vida y de la muerte, abrir y cerrar los caminos, dominar los secretos del monte y de los poderes curativos de las plantas, sustituir la mala suerte por la buena y viceversa, provocar la guerra y la destrucción, en cuyo desempeño los orichas reflejaron competencias, eficacia, fortaleza, rudeza, violencia y ejercicio de poder, característica propia de los patrones tradicionales de la masculinidad. Mientras que los roles observados en las orichas se enmarcan en la sexualidad, la maternidad, la zalamería, fabricar utensilios de uso masculino, y/o mensajeras de Olofi. (Daysi RUBIERA, 1999, p. 72-78).

${ }^{21} \quad$ Nível de dentro do sistema religioso de Santeria, em princípio, atingido apenas pelos homens. Diz-se que a partir do final do século passado, mulheres foram iniciadas como "sacerdotisas Ifá (iyanifa)".

22 Sacerdotes do segmento Ocha.

23 Embora esse processo também seja marcado pela/o orixá.

24 [... ] Hay orichas machos en "cabezas" femeninas y viceversa [... ]. Al no ser necesaria la correspondencia entre los sexos es posible diseñar una suerte de contradicción entre la autoima- 
Infere-se que mulheres e homens são catalogadas/os em padrões sexistas socialmente construídos por visões machistas e paradigmas antifeministas, o que leva à construção de estereótipos relacionados tanto à maternidade, bajulação, beleza ou mal (fofocas, bruxaria, imprudência), quanto à força, sabedoria, poder, discrição, trabalho, virilidade, respectivamente. Assim, esse controle do domínio dos homens sobre as mulheres torna impossível não apenas quebrar identidades, mas também impede qualquer participação religiosa.

Ao analisar o sistema de sexo/gênero no sistema religioso da Regla de Ocha ou Santeria, tem-se claro que o gênero não pode ser entendido como mera oposição de polos (homem-mulher), mas como elementos em continuum (Yohanka VALDÉS, 2011), concebendo-o como uma construção social. Destaca-se, assim, a importância de uma análise baseada no período e na realidade específica das sociedades, culturas e momentos históricos. Como afirma a especialista cubana Yohana Valdés (2011, p. 4, tradução própria):

[...] também é verdade que essa variabilidade espaço-temporal e sócio histórica não escapa a certos padrões ou modelos que desenham o que é tipicamente masculino ou feminino, e que localizados no final do continuum, acentuam diferenças e promovem desigualdades, que devido à "força do hábito", acreditamos que elas provêm de presentes da natureza²5.

Os postulados religiosos são agrupados como uma forma discriminatória diferente, pois colocam a religião como reprodutora de esquemas culturais que legitimam o papel secundário das mulheres. $\mathrm{O}$ canastillero ${ }^{26}$, os tipos de contêiner, os domínios e as danças marcam

gen de muchos santeros con respecto a los papeles de masculinidad y feminidad socialmente aceptados, y a la tipificación ritual atribuida a su sexo de acuerdo con la práctica y los relatos que conforman el corpus santero [... ]. (Lázara MENÉNDEZ, 2002, p. 154-155).

$25[\ldots]$ también es cierto, que esta variabilidad espacio-temporal y sociohistórica no escapa a ciertos patrones o modelos que dibujan lo típicamente masculino o femenino y que, ubicados en los extremos del continuo, acentúan diferencias y potencian desigualdades, las que por la "fuerza de la costumbre" creemos que parten de dones de la naturaleza. (Yohanka VALDÉS, 2011, p. 4).

26 Peça de mobiliário onde é colocada a representação das/os orixás. 
uma diferenciação entre mulheres e homens em termos de qualidades de delicadeza-fraqueza e resistência-rusticidade, respectivamente (Naile BRAFFO CONDE, 2015). Um exemplo disso é a ordem estabelecida pelo Órun, que geralmente determina cantar para os orixás masculinos antes dos femininos.

Portanto, homens e mulheres interpretam a religião a partir de suas subjetividades e experiências de vida e do contexto social em que operam. As exclusões explicitadas não decorrem apenas do sistema religioso de Santeria, mas também de padrões e estereótipos sexistas condicionados por um conjunto de valores, normas e ideias que, consciente ou inconscientemente, são incorporados à experiência religiosa.

A verdade é que o papel das mulheres na Santeria é essencial. No entanto, embora o número de mães de santo seja significativo e predomine nos diferentes ritos, cerimônias de natureza coletiva, e que elas sejam responsáveis pela atenção às representações das divindades dentro da sala de consagração, por outro lado, não realizam nenhuma cerimônia ou rito por conta própria, seja em qual for o nível.

Além disso, como foi dito, mesmo que na contemporaneidade possa-se ouvir sobre a iniciação de mulheres no culto Ifá, o mesmo não acontece com iniciações femininas como Oriaté, uma característica que não é mencionada em nenhum dos seus patakíes. Portanto, infere-se que o cumprimento de papéis de acordo com o gênero não é regido pelos seus pressupostos básicos, mas sim pela reprodução dos padrões machistas de uma sociedade patriarcal.

\section{CONSIDERAÇÕES FINAIS}

$\mathrm{Na}$ atualidade, as mulheres, insatisfeitas em ser apenas boas mães, esposas e/ou donas de casa, buscam auto aperfeiçoamento constante, a partir de novas formas de desenvolvimento e autorrealização. Isso não acontece apenas na vida social, mas também no campo da prática religiosa. Por isso, se satisfazem como madrinhas ou mães de santos, que trabalham para fortalecer seus papeis como liderança no interior das famílias religiosas, mesmo com as limitações apresentadas. No entanto, apesar de serem líderes dentro do grupo, não podem dirigir sozinhas as cerimônias e ritos que são realizados, nem mesmo no âmbito de suas próprias famílias religiosas. 
Uma particularidade das mulheres santeras cubanas é que o conhecimento é adquirido, principalmente, a partir da experiência sistemática das práticas, diferentemente dos homens, que o adquirem através da leitura de memórias escritas. Além disso, como o conhecimento das práticas é mais empírico e sistemático, isso não acontece da mesma maneira com as práticas sacerdotais. Portanto, infere-se que as muIheres são mais consistentes em termos de grau de comprometimento com suas práticas.

No nível da família religiosa, as mulheres predominam e, portanto, são mais envolvidas no desenvolvimento de atividades cerimoniais e de várias outras tarefas que não são executadas muito sistematicamente pelos homens, embora isso não signifique que não possam ser executadas por eles.

De maneira geral, no desempenho das práticas religiosas, as funções são delegadas, principalmente, às mulheres. Nas práticas cerimoniais coletivas do segmento Ifá, porém, recebem apoio, porque superam os homens em número - embora sejam atividades que podem ser realizadas por praticantes de ambos sexos.

Por outro lado, devido à ausência de uma instituição governante e de um livro sagrado, não há especificação de uma norma sobre a participação de um sexo ou outro nas mais diversas atividades do sistema. Isso significa que, antes dos pressupostos sociorreligiosos da Ocha, homens e mulheres são colocados no mesmo nível de possibilidade de participação. Assim, a superioridade numérica das mulheres nas diferentes atividades cerimoniais proporciona uma maior oportunidade de participação nesses espaços.

Por fim, a perspectiva de gênero mostra como as concepções religiosas são condicionadas a partir de construções sociais. Ou seja, a Regla de Ocha ou Santeria e todo o seu sistema simbólico funcionam em correspondência com as relações genéricas em vigor e os padrões de convivência são transformados com o tempo. Espera-se que as muIheres continuem em busca de empoderamento, assim como acontece em outros espaços, sejam eles religiosos ou não, com a quebra barreiras sexistas impostas pelos homens - muitas vezes reproduzidas por elas mesmas -, que impedem a liberdade de ação e o desenvolvimento do intelecto para, assim, ocupar seu devido lugar de direito. Os homens, por sua vez, devem reconhecer mais o valor religioso das mulheres como seu semelhante e não como seu oposto. 


\section{BIBLIOGRAFIA}

ARGUELLES, Anibal; RUBIERA, Daysi. Género y mito de la Regla de Ocha. La Habana: Centro de Investigaciones Psicológicas y Sociológicas, 1995.

BRAFFO CONDE, Naile. Prácticas económicas al interior de familias religiosas de La Habana. Estudio de casos. 127 f. Dissertação (Mestrado em Sociologia) - Faculdade de Filosofia, História e Sociologia da Universidade de Havana, Havana, 2015.

BRAFFO CONDE, Naile. A prática do Espiritismo na sociedade cubana. In: DAMASIO da Silva Neto, Joâo; FAGUNDES, Juliano; COLETA, Silvana. Ciência, Espiritismo e Sociedade: Coletânea 3. Goiânia: Aephus, 2021, p. 179-191.

CABRERA, Lydia. Yemayá y Ochún. Kariocha, lyalorichas y Olorichas. New York: Ediciones C.R., 1980

CASTELLANOS, Gabriela. Identidades raciales y de género em la Santeria Afro-Cubana. Historia, antropologia y fuentes orales, n. 40, 2008, pp. 167-178.

DEPARTAMENTO DE ESTUDOS SOCIORRELIGIOSOS (DESR). Religión y cambio Social. El campo religioso cubano en la década de los '90. La Habana: Ciencias Sociales, 2006.

DÍAZ, Mareleen. Concepciones generales sobre géneros. La Habana: Centro de Investigaciones Psicológica y Sociológica: Memorias II Simpósio Internacional, 2009.

FLEITAS, Reina. La identidad femenina: las encrucijadas de la igualdad y la diferencia. In: PROVEYER, Clotilde (Org.). Selección de Lecturas de Sociología y Política social de Género. La Habana: Editorial Feliz Varela, 2005, p. 38-59.

MENÉNDEZ, Lázara. Kinkamaché para gbogbo orica. Eu fodi owó, folé ayé, folé aché . In ALONSO, Aurelio (Org.). América Latina y el Caribe. Territorios religiosos y desafios para el diálogo. Buenos Aires: CLACSO-Conselho Latino-Americano de Ciências Sociais, 2008, p. 229-258.

ORTIZ, Fernando. Contrapunteo cubano del tabaco y el azúcar. Universidade Central de Las Villas: Direcção de Publicações, 1963.

QUIJANO, Aníbal. Colonialidade do poder e de/colonialidade do poder. Palestra no XXVII Congresso da Associação Latino-Americana de Sociologia, Buenos Aires, 2009.

SEGATO, Rita. Gênero, política e hibridismo na transnacionalização da cultura iorubá. Estudos Afro-Asiáticos, ano 25, n. 2, 2003, p. 333-363.

SEGATO, Rita. Gênero e colonialidade: em busca de chaves de leitura e um vocabulário estratégico descolonial. E-Cadernos, Coimbra, Edição 18, 2012, p. 106-131.

VALDÉS, Yohanka. Género y familias jóvenes en Cuba: entre tradiciones y utopias. La Habana: Centro de Investigaciones Psicológicas e Sociológicas: CD Caudales, 2011.

Submetido em: 7-4-2021

Aceito em: 24-9-2021

Mandrágora, v.27, n. 2, 2021, p. 115-133 